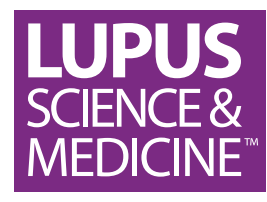

\title{
Factors associated with pain coping and catastrophising in patients with systemic lupus erythematosus: a cross-sectional study of the LuLa-cohort
}

\author{
Julia Fischin, ${ }^{1}$ Gamal Chehab, ${ }^{1}$ Jutta G Richter, ${ }^{1}$ Rebecca Fischer-Betz, ${ }^{1}$
} Borgi Winkler-Rohlfing, ${ }^{2}$ Reinhart Willers, ${ }^{1}$ Matthias Schneider ${ }^{1}$

To cite: Fischin J, Chehab G, Richter JG, et al. Factors associated with pain coping and catastrophising in patients with systemic lupus erythematosus: a crosssectional study of the LuLacohort. Lupus Science \& Medicine 2015;2:e000113. doi:10.1136/lupus-2015000113

Received 2 July 2015 Revised 12 October 2015 Accepted 17 October 2015

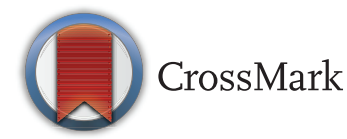

\footnotetext{
${ }^{1}$ Policlinic of Rheumatology and Hiller Research Unit Rheumatology, HeinrichHeine-University, Düsseldorf, Germany

${ }^{2}$ German Lupus Self-Help Community, Wuppertal, Germany
}

Correspondence to Dr Gamal Chehab; chehab@rheumanet.org

\section{ABSTRACT}

Objective: The aim of this study was to identify factors associated with pain coping and catastrophising in patients with systemic lupus erythematosus. Methods: All patients were participants of the lupus erythematosus long-term study, which is based on patient-reported data assessed among members of the German Lupus Erythematosus Self-Help Organization. Assessments were performed by means of a questionnaire. Among self-reported clinical data the Pain-Related Self Statements Scale (PRSS) was included. To depict significant differences univariable analyses were carried out using non-parametrical rank tests. To examine factors influencing our outcome variables, we performed a multivariable stepwise regression model including variables that presented significantly in the univariable analysis.

Results: 447 cases (94.9\% female) were analysed showing a mean catastrophising score of 1.1 (SD 0.8) and a mean coping score of 2.8 (SD 0.9) in the PRSS subscales. Higher catastrophising quartiles went along with higher experienced pain, lupus activity, fatigue, damage and decreased health related quality of life, whereas they presented inversely for coping. In our multivariable model, factors associated with catastrophising were: number of lupus-specific drugs ( $p$ value 0.004 ), pain in the last 7 days ( $p$ value 0.034), the Short Form 12 Health Survey Mental Component Summary ( $p$ value $<0.001$ ) and disease activity measured by the Systemic Lupus Activity Questionnaire ( $p$ value 0.042 ). Social participation reflected by performed leisure activities such as dancing or bowling had a positive association with coping ( $p$ value 0.006 ). In contrast, other health related physical activities and their extent had no impact on coping. A direct association between the amount of pain coping and catastrophising, as well as a great impact of the catastrophising, respectively, coping level on physical and mental functioning could be shown.

Conclusions: Reduction or increase of detected factors might lead to a modification of pain coping and catastrophising and offer an approach to more effective care in patients with SLE.

\section{KEY MESSAGES}

More pain, damage and lupus-specific drugs as well as worse mental health go along with higher levels of pain catastrophising.

- Social participation/activity might enhance pain coping and reduce catastrophising.

\section{INTRODUCTION}

Patients with systemic lupus erythematosus (SLE) suffer from possible involvement of numerous organ systems, and often from pain, ${ }^{1-3}$ fatigue, ${ }^{1}{ }^{4-6}$ sleep disorders, ${ }^{1}{ }^{5} \quad 7 \quad 8$ fear, ${ }^{9}$ depression ${ }^{9-13}$ and cognitive deficits. ${ }^{14-19}$ These complaints, either as an independent condition or associated or aggravated by the disease, are frequently linked to physical and mental restraints. Coping describes a set of intentional, goal-directed efforts people engage in to minimise physical, psychological or social harm of an event or a situation. ${ }^{20} \mathrm{It}$ encompasses behavioural and psychological strategies. These strategies can help in dealing with stress caused by the disease and are associated with a better health related quality of life (HRQoL) in patients with SLE. ${ }^{21}$ In this work we subsume the beneficial effects of coping with pain under the term 'coping'. In contrast catastrophising represents a maladaptive cognitive style employed by patients and is associated with an irrationally negative forecast of future events.

Coping is more efficient in an existing reliable social network, which may provide socioemotional support. ${ }^{22}$ The latter has a high impact on disease activity, damage and quality of life. ${ }^{23}$ As patients with SLE frequently report a poorer social support than healthy controls, ${ }^{24}$ it represents a modifiable option to enhance coping behaviour. Former studies demonstrated positive influence of 
physical activity on fatigue in $\mathrm{SLE}^{25-27}$ and pain as well as physical function in other rheumatic diseases. ${ }^{28}$ Referring to these results we hypothesised that physical activity might have an influence on coping strategies as well.

In contrast it is known that catastrophising may have serious impact on chronically ill patients in general and patients with SLE in particular. ${ }^{29}$ Maladaptive coping characterised by catastrophising is associated with increased pain experience ${ }^{30}$ and predicts higher levels of pain in patients with chronic rheumatic diseases (eg, fibromyalgia syndrome and rheumatoid arthritis). ${ }^{31}$ Furthermore, catastrophising and maladaptive coping strategies are linked to higher levels of functional impairment and depression in rheumatoid arthritis ${ }^{32}$ and SLE. ${ }^{33}$ Numerous other studies verified the negative influence of catastrophising, respectively, suboptimal coping strategies on the outcome of various other chronic diseases by occurrence of depressive symptoms, ${ }^{34} 35$ reduced cognitive performance ${ }^{36}$ or even an increased risk for suicide. ${ }^{37}$

As psychological interventions and education are able to increase coping abilities in patients with SLE and can thus improve their quality of life,$^{38}$ it is of major importance to explore the main stressors that affect coping behaviour.

The aim of this study was to identify factors that are associated with our outcomes pain coping and catastrophising in patients with long-standing SLE and to detect possible susceptible targets for intervention. Therefore, we analysed several demographic parameters, disease related outcomes, physical activity, physical and mental functioning, social participation and their impact on pain coping and catastrophising.

\section{METHODS}

The data was collected within the lupus erythematosus long-term study (LuLa-study), a prospective, patientcentred study investigating the long-term management and course of disease as well as quality of life in patients with SLE. Data collection started in 2001 with annual postal questionnaires among members of the German Lupus Erythematosus Self-Help Organisation. Inclusion criteria were a reported diagnosis of SLE, being a member of the German Lupus Erythematosus Self-Help Organisation and having returned the completed questionnaire. Prior evaluation of the LuLa cohort showed that its data is comparable to physician-reported data and thereby is representative of patients with SLE in Germany. ${ }^{39}$ In 2009 we surveyed for 18 comorbidities (hypertension, myocardial infarction, stroke, chronic kidney damage, diabetes, cancer, chronic respiratory disease, chronic liver damage, chronic gastrointestinal disorders, hypercholesterolaemia, mental illness, arthrosis, scarring changes of skin, osteoporosis, fibromyalgia, thrombosis, miscarriages, early menopause), lupusspecific drugs, sociodemographic characteristics, inability to work, degree of disability (\%), HRQoL measured by the Short Form 12 Health Survey (SF-12), ${ }^{40}$ 'pain in the last 7 days' (NRS 0-10), 'impairment in the last 7 days' (NRS 0-10), disease flares during the last 3 months, disease activity measured by the Systemic Lupus Activity Questionnaire (SLAQ), ${ }^{41}$ health related physical activity assessed by the Freiburg Questionnaire for Physical Activity (FFkA), ${ }^{42}$ situation-specific aspects of the patients' cognitive coping with pain ('catastrophising' and 'coping'), measured by the Pain-Related Self Statements Scale (PRSS), ${ }^{43}$ fatigue measured by the Vanderbilt Fatigue Score (VFS), ${ }^{44}$ and the Systemic Lupus International Collaborating Clinics/American College of Rheumatology Damage Index (SLICC/ACR DI) ${ }^{45-47}$ Most assessments were self-reported, only for the SLICC/ACR DI patients were asked to let their physician complete the questionnaire. All questionnaire items were assessed at the same time. Due to the questionnaire's length specific instruments regarding socioemotional support had to be omitted. Therefore we used a construct using other variables.

\section{Measures}

\section{Pain-Related Self Statements Scale}

Detection of coping strategies was carried out by the German version of the PRSS, which is intended to assess situation-specific cognitions that either promote or hinder attempts to cope with pain. The PRSS includes 18 items, which are subsumed into two nine-item subscales, termed 'catastrophising' and 'coping'. Items are rated on a numerical rating scale, describing how often a statement enters the patients' minds when they experience severe pain $(0=$ almost never to $5=$ almost always $)$. Questionnaire's reliability, validity and sensitivity to change were proven by Flor $e t a t^{43}$ in a sample of 415 patients including 120 patients with chronic pain suffering from various rheumatic disorders, 213 patients suffering from chronic back pain, 44 patients with temporomandibular pain and dysfunction (TMPD) and 38 healthy controls.

Both subscales demonstrated to be valid and sensitive to change, and to be closely related to pain intensity and interference from pain experiences. There are no cut-off-values defined for high or low coping, respectively, catastrophising, but results from healthy controls showed a relatively low catastrophising score of 0.9 (SD 0.8 ) and a relatively high coping score of 3.4 (SD 1.1). ${ }^{43}$ In comparison patients with chronic back pain depicted a catastrophising score of 2.0 (SD 1.2) and a coping score of 3.0 (SD 0.9) and patients with TMPD a catastrophising score of 2.3 (SD 1.0) and a coping score of 2.8 (SD 0.7). ${ }^{43}$

\section{Short-Form 12 Health Survey}

The 12-item short-form (SF-12) is based on the 36-item short-form (SF-36) ${ }^{40}$ and is used to survey a population's health status. The SF-12 provides comparable results to the SF-36. ${ }^{48}$ Two subscales can be extracted: The 
Physical Component Summary (PCS) and the Mental Component Summary (MCS). Because of the questionnaire's size limitations we adopted the MCS as a substitute for a more extensive inquiry of the individual factors affecting mental health (eg, depression, anxiety disorders). The MCS has repeatedly proven to be a valid instrument for identifying and assessing the severity of depression and anxiety. ${ }^{50}$ Additionally the physical functioning index of the SF-36 (SF-36-pfi) ${ }^{51}$ was assessed.

\section{Systemic Lupus Activity Questionnaire}

In order to screen for current disease activity the SLAQ which is based on the Systemic Lupus Activity Measure, ${ }^{52}$ was applied. The SLAQ is a patient-reported questionnaire consisting of 24 items, which aims at detection of disease activity in patients with SLE. ${ }^{41}$ In large observational, community-based cohorts of people with SLE it demonstrated to have an adequate reliability, construct validity and responsiveness. ${ }^{53}$ Additionally, we used the supplemental SLAQ item 1 which assesses the occurrence and severity of disease flares (no/mild/ moderate/severe flare) during the last 3 months.

\section{Systemic Lupus International Collaborating Clinics/American} College of Rheumatology Damage Index

In order to detect damage in patients with SLE the SLICC/ACR DI was used. ${ }^{45-47}$ It records damage in nine different organ systems, which accrued since disease onset and persisted for at least 6 months.

\section{Freiburg Questionnaire for Physical Activity}

The cohort's health related physical activity was assessed by the FFkA. ${ }^{42}$ It consists of 12 questions related to the duration of performed basic activities, recreational activities and sport activities per week. In the context of this study, a calculation of leisure activity was carried out using the items 'dancing' and 'bowling'. As these two social leisure activities, contrary to walking, using exercise machines, and so on, can only be performed in company, we considered them as a proxy measure for patients' 'social participation'.

Further questions considered the incidence of sick leave during the past 12 months, the number of weeks on sick leave and the degree of disability. The degree of disability is a standardised official governmental approval of non-temporary bodily or psychological disability that is due to an irregular state. Severity is graded from $20 \%$ to $100 \%$.

\section{Statistical analysis}

Collected data were analysed with the statistical software programme IBM SPSS Statistics V.19. A descriptive analysis was carried out by the calculation of mean, median, $\mathrm{SD}$, minimum and maximum, where applicable.

By means of the PRSS the 'catastrophising' and 'coping' subscales were calculated. To assess the association between the two subscales and other outcome parameters quantitatively, we studied the four quartiles of the subscales (lower quartile $<25 \%, 25-50 \%, 50-75 \%$, upper quartile $>75 \%$ ) in relation to each outcome parameter. Spearman's correlations were used for ordinal-scaled and Pearson's correlations for interval-scaled data. Because of the subscales skew distribution univariable analyses (UVA) were carried out using non-parametrical rank tests to depict significant differences. In cases of two independent samples the Mann-Whitney $\mathrm{U}$ test and in cases of multiple independent samples the Kruskal-Wallis test was applied. p Values less than 0.05 were considered statistically significant for all tests. In order to prevent an $\alpha$ error due to multiple testing, adjustment of the $\mathrm{p}$ values by means of the Bonferroni correction was performed. Consequently, levels of statistical significance were defined at $\mathrm{p}<\alpha / \mathrm{k}$ $(\alpha=0.05 / \mathrm{k}=$ number of tests $)$.

To examine factors influencing our outcome variables 'catastrophising' and 'coping' among patients, we used a stepwise regression model to reduce the number of variables. Those variables that presented as significant in the UVA, entered this multivariable analysis (MVA) model including clinical and demographic parameters (SF-12 PCS, SF-12 MCS, SLAQ score, VFS, SLICC/ACR DI, number of concomitant diseases, number of lupusspecific drugs, inability to work, degree of disability (\%), pain in the last 7 days, impairment in the last 7 days, disease flares during the last 3 months and social participation). Missing values were not imputated. Analysed number of cases may vary due to missing values. In MVA only complete cases were included.

\section{RESULTS}

The LuLa 2009 cohort included 620 patients of whom 173 reported no pain $(86,1 \%)$ or did not answer the PRSS questionnaire $(13,9 \%)$. This resulted in 447 cases (94.9\% female) with a mean age of 52.0 years (SD 12.5) and mean disease duration of 16.1 years (SD 8.1), which were included in the analyses. The analysis of the PRSS subscales showed a mean catastrophising score of 1.1 (SD 0.8) and a mean coping score of 2.8 (SD 0.9). Details and further results of self-reported disease activity, damage, current treatment, employment status, assessments of general health and physical functioning are listed in table 1.

Table 2 opposes four groups of different catastrophising and coping levels. Higher catastrophising centiles (upper quartile) are associated with higher experienced pain, current lupus activity (SLAQ score), fatigue (VFS score), damage (SLICC/ACR DI scores) and a decrease of HRQoL domains (SF-36-pfi, SF-12 PCS and SF-12 MCS) whereas they present inversely for coping (table 2).

Nine out of the 18 acquired comorbidities showed significant association to the PRSS subscale catastrophising with higher catastrophising means in presence of comorbidities than in absence (table 3 ).

A relationship between coping and comorbidities was not observed. Three of the nine comorbidities with 
Table 1 Sample description (447 patients)

\begin{tabular}{|c|c|c|c|c|}
\hline & Per cent & Mean \pm SD & Range & $\mathbf{n}$ \\
\hline Age in 2009 (years) & & $52.0 \pm 12.5$ & 14-86 & 447 \\
\hline Disease duration in 2009 (years) & & $16.1 \pm 8.1$ & $5-49$ & 440 \\
\hline Medication & & & & 447 \\
\hline NSAIDs & 29.3 & & & \\
\hline Cortisone $\leq 7.5 \mathrm{mg}$ & 53.0 & & & \\
\hline Cortisone $>7.5 \mathrm{mg}$ & 16.1 & & & \\
\hline Antimalarials & 41.2 & & & \\
\hline Methotrexate & 9.8 & & & \\
\hline Azathioprine & 18.8 & & & \\
\hline Ciclosporine & 2.2 & & & \\
\hline Cyclophosphamide & 1.1 & & & \\
\hline Mycofenolatmofetil (MMF) & 13.0 & & & \\
\hline Medication groups & & & & 447 \\
\hline NSAIDs or no medication & 14.3 & & & \\
\hline Antimalarials and/or steroids, possible NSAIDs & 40.3 & & & \\
\hline Immunosuppressants, possible NSAIDs, antimalarials, steroids & 45.4 & & & \\
\hline Occupation type & & & & 443 \\
\hline Retired & 50.1 & & & \\
\hline Employees & 29.6 & & & \\
\hline Unemployed & 12.9 & & & \\
\hline Worker & 3.8 & & & \\
\hline Self-employed & 2.9 & & & \\
\hline Pupils/students & 0.7 & & & \\
\hline Physical functioning (0-100) (SF-36-pfi) & & $62.4 \pm 27.5$ & $0-100$ & 447 \\
\hline SF-12 PCS & & $37.9 \pm 11.0$ & $11.0-62.9$ & 414 \\
\hline SF-12 MCS & & $46.1 \pm 11.7$ & $18.4-69.5$ & 414 \\
\hline SLAQ score & & $14.8 \pm 7.0$ & $0-37$ & 446 \\
\hline VFS score & & $26.7 \pm 19.2$ & $0-70$ & 424 \\
\hline SLICC/ACR DI & & $2.8 \pm 2.9$ & $0-21$ & 407 \\
\hline PRSS catastrophising & & $1.1 \pm 0.8$ & $0-4.1$ & 426 \\
\hline PRSS coping & & $2.8 \pm 0.9$ & $0-4.8$ & 431 \\
\hline
\end{tabular}

significant association remained significant after Bonferroni correction ( $p$ value $<0.003$ ). These three comorbidities 'chronic gastrointestinal disorders' ( $p$ value 0.002 ), 'mental illness' ( $p$ value $<0.001$ ) and 'scarring changes of skin' ( $p$ value $<0.001$ ) were included in the MVA but did not show significant association to catastrophising any more.

In total, 52 patients $(11.6 \%)$ participated in the bowling and dancing activities, whereby 31 (7.0\%) participated in dancing, $13(2.9 \%)$ in bowling and $8(1.8 \%)$ in both. This was considered as social participation.

As shown in table 4, coping presented statistical significance for 'social participation' in the UVA ( $p$ value 0.001 ) and the MVA ( $p$ value 0.006 ). Mean coping was significantly higher in participants with social participation than without (mean 3.2 vs 2.8). 'SF-12 MCS' was significant for both PRSS subscales in the UVA ( $p$ value catastrophising $<0.001$; p value coping 0.001) but only significant for catastrophising in the MVA $(p<0.001)$. Catastrophising demonstrated a multitude of significant correlations with different disease parameters and conditions among others SF-12, SLAQ, SLICC/ACR DI and disease flares during last 3 months. The variables 'pain in the last 7 days' (correlation coefficient 0.420), 'impairment in the last 7 days' (correlation coefficient 0.388), fatigue (VFS score) (correlation coefficient 0.367) and disease activity (SLAQ score) (correlation coefficient 0.475 ) evinced the highest correlation coefficients (table 4).

After Bonferroni correction all significant variables of the UVA were included in the MVA. Four variables reached statistical significance regarding catastrophising ('number of lupus-specific drugs' ( $p$ value 0.004), 'pain in the last 7 days' ( $p$ value 0.034 ), 'SF-12 MCS' ( $p$ value $<0.0001$ ), and 'SLAQ score' ( $\mathrm{p}$ value 0.042$)$ ), and one ('social participation'; $p$ value 0.006 ) regarding coping.

Parameters for basic, sports and leisure activities, assessed by the FFkA, were also compared with the two PRSS subscales. However, none of the activity parameters or the extent of health related physical activity showed a coherent statistical significance regarding pain coping and catastrophising. 
Table 2 Characteristics of PRSS catastrophising and coping groups split by quartiles

\begin{tabular}{|c|c|c|c|c|c|c|c|c|}
\hline & \multicolumn{4}{|c|}{ PRSS catastrophising } & \multicolumn{4}{|c|}{ PRSS coping } \\
\hline & $\begin{array}{l}\text { Lower } \\
\text { quartile } \\
(0-0.4)\end{array}$ & $\begin{array}{l}25-50 \% \\
(0.5-1.0) \\
\end{array}$ & $\begin{array}{l}50-75 \% \\
(1.1-1.7) \\
\end{array}$ & $\begin{array}{l}\text { Upper } \\
\text { quartile } \\
(1.8-4.1) \\
\end{array}$ & $\begin{array}{l}\text { Lower } \\
\text { quartile } \\
(0-2.3)\end{array}$ & $\begin{array}{l}25-50 \% \\
(2.4-2.9) \\
\end{array}$ & $\begin{array}{l}50-75 \% \\
(3.0-3.4) \\
\end{array}$ & $\begin{array}{l}\text { Upper } \\
\text { quartile } \\
(3.5-4.8)\end{array}$ \\
\hline$n$ & 113 & 101 & 114 & 98 & 131 & 106 & 102 & 92 \\
\hline Age in 2009 & 50.8 & 53.2 & 51.0 & 52.4 & 51.6 & 52.5 & 51.4 & 51.0 \\
\hline $\begin{array}{l}\text { Disease duration in } \\
2009\end{array}$ & 16.0 & 16.4 & 16.0 & 15.8 & 16.6 & 15.9 & 15.6 & 15.7 \\
\hline Coping & 2.8 & 2.9 & 2.9 & 2.7 & 1.6 & 2.6 & 3.2 & 3.9 \\
\hline Catastrophising & 0.2 & 0.7 & 1.4 & 2.2 & 1.2 & 1.3 & 1.1 & 0.9 \\
\hline SF-36-pfi & 73.3 & 65.5 & 59.3 & 51.6 & 62.8 & 57.0 & 63.9 & 66.5 \\
\hline SF-12 PCS & 41.6 & 38.8 & 36.0 & 34.9 & 38.8 & 36.5 & 37.6 & 38.6 \\
\hline SF-12 MCS & 52.2 & 49.2 & 43.6 & 40.0 & 44.5 & 43.1 & 48.3 & 49.8 \\
\hline SLAQ score & 10.5 & 13.6 & 17.1 & 18.2 & 14.7 & 16.4 & 14.4 & 13.4 \\
\hline VFS score & 17.9 & 24.2 & 30.6 & 34.4 & 27.9 & 29.1 & 25.9 & 22.0 \\
\hline SLICC/ACR DI & 1.8 & 2.6 & 3.1 & 3.6 & 2.5 & 3.5 & 3.1 & 2.2 \\
\hline Pain (last 7 days) & 2.6 & 3.4 & 4.3 & 5.1 & 3.8 & 4.2 & 3.8 & 3.3 \\
\hline
\end{tabular}

Data are means illustrated separately for PRSS catastrophising and PRSS coping. Different levels of catastrophising resp. coping are represented in four quartiles.

n, number of cases; PRSS, Pain-Related Self Statements Scale; SF-12 MCS, SF-12 Mental Component Summary; SF-12 PCS, SF-12 Physical Component Summary; SF-36-pfi, 36-item short-form physical functioning index; SLAQ, Systemic Lupus Activity Questionnaire; SLICC/ACR DI: Systemic Lupus International Collaborating Clinics/American College of Rheumatology Damage Index; VFS, Vanderbilt Fatigue Score.

\section{DISCUSSION}

Despite the numerous recent advances in research and clinical treatment, SLE keeps being an incurable chronic disease with a huge impact on persons' lives by affecting patients' physical and mental functioning. Former studies illustrated that coping capacities help in dealing with the disease and are associated with a better HRQoL. ${ }^{21}$
The PRSS results from our cross-sectional study in SLE depicted significantly worse catastrophising and coping scores than reported from healthy controls. ${ }^{43}$ Coping presented worse in our cohort compared with patients with chronic pain but was similar to patients suffering from TMPD. ${ }^{43}$ In contrast our cohort presented significantly less catastrophising. ${ }^{43}$ As pain related catastrophising differs in younger and older adults $^{55}$ these

Table 3 Univariable analysis: comorbidities $(n=447)$

\begin{tabular}{|c|c|c|c|}
\hline \multirow[b]{2}{*}{ Comorbidity } & \multicolumn{2}{|c|}{ Catastrophising mean \pm SD (n) } & \multirow[b]{2}{*}{ p Value catastrophising } \\
\hline & Comorbidity=yes & Comorbidity $=$ no & \\
\hline Diabetes & $1.4 \pm 0.8(8)$ & $1.1 \pm 0.8(375)$ & 0.034 \\
\hline Chronic respiratory disease & $1.2 \pm 0.8(36)$ & $1.1 \pm 0.8(349)$ & 0.031 \\
\hline Chronic liver damage & $1.5 \pm 0.9(10)$ & $1.1 \pm 0.8(370)$ & 0.007 \\
\hline Chronic gastrointestinal disorders & $1.3 \pm 0.8(26)$ & $1.0 \pm 0.8(355)$ & 0.002 \\
\hline Mental illness & $1.7 \pm 0.8(38)$ & $1.0 \pm 0.7(342)$ & $<0.001$ \\
\hline Arthrosis & $1.2 \pm 0.8(86)$ & $1.0 \pm 0.7(295)$ & 0.021 \\
\hline Scarring changes of skin & $1.3 \pm 0.8(47)$ & $1.0 \pm 0.8(332)$ & $<0.001$ \\
\hline Fibromyalgia & $1.4 \pm 0.8(27)$ & $1.1 \pm 0.8(347)$ & 0.014 \\
\hline Stroke & $1.9 \pm 0.9(9)$ & $1.1 \pm 0.8(376)$ & 0.023 \\
\hline Hypertension & & & NS \\
\hline Myocardial infarction & & & NS \\
\hline Chronic kidney damage & & & NS \\
\hline Cancer & & & NS \\
\hline Hypercholesterolaemia & & & NS \\
\hline Osteoporosis & & & NS \\
\hline Thrombosis & & & NS \\
\hline Miscarriages & & & NS \\
\hline Early menopause & & & NS \\
\hline
\end{tabular}


Table 4 Findings of the univariable analysis (UVA) and multivariable analysis (MVA)

\begin{tabular}{|c|c|c|c|c|c|c|}
\hline \multirow[b]{2}{*}{ Variable name } & \multicolumn{3}{|c|}{ Catastrophising } & \multicolumn{3}{|l|}{ Coping } \\
\hline & $\begin{array}{l}\text { p Value } \\
\text { (UVA) }\end{array}$ & $\begin{array}{l}\text { Correlation } \\
\text { coefficient }\end{array}$ & $\begin{array}{l}\text { p Value } \\
\text { (MVA) }\end{array}$ & $\begin{array}{l}\text { p Value } \\
\text { (UVA) }\end{array}$ & $\begin{array}{l}\text { Correlation } \\
\text { coefficient }\end{array}$ & $\begin{array}{l}\text { p Value } \\
\text { (MVA) }\end{array}$ \\
\hline SF-12 PCS & $<0.001$ & $-0.250^{\star \star}$ & & NS & & \\
\hline SF-12 MCS & $<0.001$ & $-0.443^{\star \star}$ & $<0.001$ & 0.001 & $0.171^{\star \star}$ & NS \\
\hline SLAQ score & $<0.001$ & $0.475^{\star}$ & 0.042 & NS & & NS \\
\hline VFS score & $<0.001$ & $0.367^{*}$ & & NS & & \\
\hline SLICC/ACR DI & $<0.001$ & $0.192^{*}$ & & NS & & \\
\hline $\begin{array}{l}\text { Number of concomitant } \\
\text { diseases }\end{array}$ & $<0.001$ & $0.202^{*}$ & & NS & & \\
\hline $\begin{array}{l}\text { Number of lupus-specific } \\
\text { drugs }\end{array}$ & $<0.001$ & $0.204^{*}$ & 0.004 & NS & & NS \\
\hline Inability to work & 0.001 & $0.213^{*}$ & & NS & & \\
\hline Degree of disability (\%) & 0.003 & $0.169^{\star \star}$ & & NS & & \\
\hline Pain in the last 7 days & $<0.001$ & $0.420^{\star}$ & 0.034 & NS & & NS \\
\hline $\begin{array}{l}\text { Impairment in the last } \\
7 \text { days }\end{array}$ & $<0.001$ & $0.388^{*}$ & & NS & & \\
\hline $\begin{array}{l}\text { Disease flares during last } \\
3 \text { months }\end{array}$ & $<0.001$ & $0.280^{*}$ & & NS & & \\
\hline Social participation & $\mathrm{NS}^{\mathrm{X}}$ & & NS & $0.001^{x}$ & & 0.006 \\
\hline \multicolumn{7}{|c|}{$\begin{array}{l}\text { Data are } p \text { values and correlation coefficients. Correlations were carried out by Spearman's }\left(^{*}\right) \text { and Pearson's }\left(^{* *}\right) \text { correlations. The } p \text { values } \\
\text { for catastrophising and coping in the UVA were derived from Spearman's and Pearson's correlation or from the Mann-Whitney U test }(x) \text {. The } \\
p \text { values for catastrophising and coping in the MVA were derived from ANOVA (analysis of variance). Only complete cases ( } n=323) \text { were } \\
\text { included in the MVA. } \\
\text { SF-12 MCS, SF-12 Mental Component Summary; SF-12 PCS, SF-12 Physical Component Summary; SLAQ, Systemic Lupus Activity } \\
\text { Questionnaire; SLICC/ACR DI, Systemic Lupus International Collaborating Clinics/American College of Rheumatology Damage Index; VFS, } \\
\text { Vanderbilt Fatigue Score. }\end{array}$} \\
\hline
\end{tabular}

differences may partly be explained by the younger age in Flor's cohort ${ }^{43}$ (42.4 years vs 52.1 years). Compared with patients with fibromyalgia ${ }^{56}$ our SLE cohort showed lower amount of catastrophising and coping. This might be attributed to a high rate of depression in the fibromyalgia cohort and to the inclusion of patients participating in pain management programmes. ${ }^{56}$

We identified valuable parameters that seem to influence the occurrence of either catastrophising or coping in patients with SLE. Yet it should be noted that crosssectional studies limit the ability to make causal assumptions between the predictors and outcomes.

First, our results demonstrated that patients with SLE with our above mentioned comorbidities catastrophise more than those without, which emphasises the impact of these specific comorbidities in patients with SLE. Studies from other chronic diseases support our findings. ${ }^{57} 58$ Thus it is of importance that 'scarring changes of skin', ${ }^{59}$ 'mental illness' ${ }^{60}$ and 'gastrointestinal disorders ${ }^{61}$ might also be attributable to lupus and are preventable by an early and optimised lupus therapy.

Second, we found statistically significant associations between the number of lupus-specific drugs, pain, 'SF-12 MCS', damage and catastrophising. In detail the high correlation between the experienced pain in the last 7 days' and catastrophising (Table 4) confirms findings from former studies depicting that the experience of pain in rheumatological disorders is closely related to catastrophising. ${ }^{29} 3162$
The moderate correlation between 'SF-12 MCS' (a proxy for depression and anxiety) and catastrophising presented in our work substantiates the fact that suboptimal mental health is associated with catastrophising, which has already been demonstrated in former studies. $^{34-37}$

Besides, we showed that the "number of lupus-specific drugs' significantly increases with a higher catastrophising score. Yet, it has not been clarified whether a rising amount of medication leads to increased catastrophising or vice versa. Consequently, physicians should be aware of possible aggravations and ought to apply objective criteria for the choice of medication.

Third, referring to coping, the variable 'social participation' reached statistical significance in the MVA. This is allegeable by the numerous positive effects associated with an existing social network and the provided socioemotional support. ${ }^{22}$ An obviously anticipated reciprocal correlation between the amount of pain coping and catastrophising could likewise be shown in our work. This indicates that a sufficient manner of coping (eg, by increasing social participation/activity) might be helpful to reduce catastrophising and consequently improve physical and mental functioning in SLE (Table 2).

In addition, it needs to be considered that catastrophising, pain, disability and mood-emotional functioning might bias the questionnaire's response behaviour. Patients might indicate a poorer health condition than it actually is because of their tendency to catastrophise, 
their experienced severity of pain, their physical functioning and/or psychological condition. Our results depicted in table 2 support this hypothesis, as the group of the strongest catastrophiser (upper quartile) showed poorer values for all mentioned variables than the others (lower quartile, 25-50\%, 50-75\%). A similar observation was published by Mancuso et $a l^{63}$ who detected that patients with asthma with more depressive symptoms reported worse HRQoL than patients with asthma with similar disease activity but fewer depressive symptoms. These findings emphasise that psychological conditions might have an impact on patients' response behaviour.

Most of our identified key factors that interact with pain coping strategies (number of lupus-specific drugs, pain, mental health, disease activity) have been identified as disease aggravating factors in the SLE treat-to-target recommendations published in 2014. ${ }^{64}$ They can be modified by an effective therapy which is regularly adjusted to lupus manifestations and individual needs. Furthermore pain and mental health as well as pain coping and catastrophising can effectively be improved by using psychological or psychoeducational interventions, ${ }^{38} 65-68$ which among others aim at increasing the self-efficacy of patients.

\section{Limitations}

There are certain limitations to this study. In favour of other items there was no implementation of further questions regarding social participation and social environment in the LuLa study. Our variable 'social participation' was constructed by use of two variables ('dancing' and 'bowling'), not considering other social activities. It should be mentioned though that other solitary activities (eg, 'taking a walk', 'cycling'), which by the way can be performed also in groups and not only alone, as well as the extent of health related physical activity, assessed by parts of the FFkA, ${ }^{42}$ did not show statistical significance regarding coping nor regarding catastrophising. For further evaluation future studies should consider other activities in detail as well (eg, membership with active participation in societies or clubs, team sports or regular leisure activities in groups) in order to provide better recommendations for optimal patient care.

As the surveyed participants were all members of the German Lupus Erythematosus Self-Help Organisation, we were not able to evaluate the impact of support groups. A distinction between passive and active members (eg, participants in support group meetings, activities or online discussion groups) could point out further strategies to improve coping and minimise catastrophising.

To our knowledge our sample included predominantly Caucasians and did not include other ethnical groups. In addition we are not able to comment on catastrophising and coping in recently diseased patients. Hence, further studies in an inception cohort are necessary in order to evaluate coping strategies in early disease.

\section{CONCLUSION}

Our work points out that in order to optimise pain coping and catastrophising in the care of patients with SLE and to affect patients' physical and mental functioning, positive factors should be protected and promoted and negative factors need to be prevented. In this context social participation represents an essential positive factor whereas negative ones include disease activity, pain, impairments and an extensive lupus-specific medication. Further studies are necessary to determine which patients benefit most from a psychoeducation and to identify the impact of revised modifiable parameters on coping strategies.

Contributors JF and GC contributed equally to this work and had full access to all of the data in the study and take responsibility for the integrity of the data and the accuracy of the data analysis. Study design: GC, JR, RF-B, BW-R, MS. Acquisition of data: GC, BW-R, RF-B, JR. Statistical analysis: GC, JF, RW. Analysis and interpretation of data: GC, JF, JR, RF-B, RW, MS. Manuscript preparation: JF, GC, JR, RF-B, MS.

Funding The LuLa-study is supported by unrestricted grants from GlaxoSmithKline and UCB Pharma and by the German Lupus Erythematosus Self-Help Organisation.

Competing interests MS, GC, RF-B and JR receive unrestricted grants from GlaxoSmithKline and UCB Pharma for performing the LuLa-study. JF, BW-R and RW have nothing to declare.

Data sharing statement Additional information about the data set and analyses are available upon request.

Ethics approval Heinrich-Heine-University Düsseldorf Institutional Review Board (Study number 2260 and 3708).

Provenance and peer review Not commissioned; externally peer reviewed.

Open Access This is an Open Access article distributed in accordance with the Creative Commons Attribution Non Commercial (CC BY-NC 4.0) license, which permits others to distribute, remix, adapt, build upon this work noncommercially, and license their derivative works on different terms, provided the original work is properly cited and the use is non-commercial. See: http:// creativecommons.org/licenses/by-nc/4.0/

\section{REFERENCES}

1. Colangelo K, Pope J, Peschken C. The minimally important difference for patient reported outcomes in systemic lupus erythematosus including the HAQ-DI, pain, fatigue, and SF-36. $J$ Rheumatol 2009;36:2231-7.

2. Greco CM, Rudy TE, Manzi S. Adaptation to chronic pain in systemic lupus erythematosus: applicability of the multidimensional pain inventory. Pain Med 2003;4:39-50.

3. Zink A, Fischer-Betz R, Thiele K, et al. Health care and burden of illness in systemic lupus erythematosus compared to rheumatoid arthritis: results from the National Database of the German Collaborative Arthritis Centres. Lupus 2004;13:529-36.

4. Burgos P, Alarcón G, McGwin G, et al. Disease activity and damage are not associated with increased levels of fatigue in systemic lupus erythematosus patients from a multiethnic cohort: LXVII. Arthritis Rheum 2009;61:1179-86.

5. Tench CM, McCurdie I, White PD, et al. The prevalence and associations of fatigue in systemic lupus erythematosus. Rheumatology (Oxford) 2000;39:1249-54.

6. Taylor J, Skan J, Erb N, et al. Lupus patients with fatigue-is there a link with fibromyalgia syndrome? Rheumatology (Oxford) 2000;39:620-3.

7. Costa D, Bernatsky S, Dritsa M, et al. Determinants of sleep quality in women with systemic lupus erythematosus. Arthritis Rheum 2005;53:272-8.

8. Greenwood K, Lederman L, Lindner H. Self-reported sleep in systemic lupus erythematosus. Clin Rheumatol 2008;27:1147-51. 
9. Bachen E, Chesney M, Criswell L. Prevalence of mood and anxiety disorders in women with systemic lupus erythematosus. Arthritis Rheum 2009;61:822-9.

10. Doria A, Rinaldi S, Ermani M, et al. Health-related quality of life in Italian patients with systemic lupus erythematosus. II. Role of clinical, immunological and psychological determinants. Rheumatology (Oxford) 2004;43:1580-6.

11. Greco C, Kao A, Sattar A, et al. Association between depression and coronary artery calcification in women with systemic lupus erythematosus. Rheumatology (Oxford) 2009;48:576-81.

12. Panopalis $P$, Julian L, Yazdany $J$, et al. Impact of memory impairment on employment status in persons with systemic lupus erythematosus. Arthritis Rheum 2007;57:1453-60.

13. Philip E, Lindner H, Lederman L. Relationship of illness perceptions with depression among individuals diagnosed with lupus. Depress Anxiety 2009;26:575-82.

14. Hanly J, McCurdy G, Fougere L, et al. Neuropsychiatric events in systemic lupus erythematosus: attribution and clinical significance. $J$ Rheumatol 2004;31:2156-62.

15. Hanly J, Su L, Farewell V, et al. Prospective study of neuropsychiatric events in systemic lupus erythematosus. $J$ Rheumatol 2009;36:1449-59.

16. Hanly JG, Urowitz MB, Su L, et al. Prospective analysis of neuropsychiatric events in an international disease inception cohort of patients with systemic lupus erythematosus. Ann Rheum Dis 2010;69:529-35.

17. Brey RL, Holliday SL, Saklad AR, et al. Neuropsychiatric syndromes in lupus: prevalence using standardized definitions. Neurology 2002;58:1214-20.

18. Hanly JG, Urowitz MB, Sanchez-Guerrero J, et al. Neuropsychiatric events at the time of diagnosis of systemic lupus erythematosus: an international inception cohort study. Arthritis Rheum 2007;56:265-73.

19. Petri $\mathrm{M}$, Naqibuddin $\mathrm{M}$, Carson $\mathrm{K}$, et al. Cognitive function in a systemic lupus erythematosus inception cohort. J Rheumatol 2008;35:1776-81.

20. Lazarus RS, Folkman S. Stress, appraisal and coping. New York, NY: Springer, 1984.

21. Hyphantis T, Palieraki K, Voulgari PV, et al. Coping with health-stressors and defence styles associated with health-related quality of life in patients with systemic lupus erythematosus. Lupus 2011;20:893-903.

22. Siegrist J. Medizinische Soziologie: Mit 18 Tabellen. 6th edn. München, [u.a.]: Elsevier, Urban \& Fischer, 2005

23. Mazzoni D, Cicognani E. Social support and health in patients with systemic lupus erythematosus: a literature review. Lupus 2011;20:1117-25.

24. Zheng $\mathrm{Y}, \mathrm{Ye} \mathrm{D}, \mathrm{Pan} \mathrm{H}$, et al. Influence of social support on health-related quality of life in patients with systemic lupus erythematosus. Clin Rheumatol 2009;28:265-9.

25. Robb-Nicholson LC, Daltroy L, Eaton H, et al. Effects of aerobic conditioning in lupus fatigue: a pilot study. $\mathrm{Br} J$ Rheumatol 1989:28:500-5.

26. Tench CM, McCarthy J, McCurdie I, et al. Fatigue in systemic lupus erythematosus: a randomized controlled trial of exercise. Rheumatology (Oxford) 2003;42:1050-4.

27. Yuen HK, Holthaus K, Kamen DL, et al. Using Wii Fit to reduce fatigue among African American women with systemic lupus erythematosus: a pilot study. Lupus 2011;20:1293-9.

28. Kelley GA, Kelley KS, Hootman JM, et al. Effects of community-deliverable exercise on pain and physical function in adults with arthritis and other rheumatic diseases: a meta-analysis. Arthritis Care Res (Hoboken) 2011;63:79-93.

29. Somers TJ, Kurakula PC, Criscione-Schreiber L, et al. Self-efficacy and pain catastrophizing in systemic lupus erythematosus: relationship to pain, stiffness, fatigue, and psychological distress. Arthritis Care Res (Hoboken) 2012;64:1334-40.

30. Sullivan MJ, Thorn B, Haythornthwaite JA, et al. Theoretical perspectives on the relation between catastrophizing and pain. Clin $J$ Pain 2001;17:52-64.

31. Hassett AL, Cone JD, Patella SJ, et al. The role of catastrophizing in the pain and depression of women with fibromyalgia syndrome. Arthritis Rheum 2000;43:2493-500.

32. Keefe FJ, Brown GK, Wallston KA, et al. Coping with rheumatoid arthritis pain: catastrophizing as a maladaptive strategy. Pain 1989;37:51-6.

33. McCracken LM, Semenchuk EM, Goetsch VL. Cross-sectional and longitudinal analyses of coping responses and health status in persons with systemic lupus erythematosus. Behav Med 1995;20:179-87.
34. Vollman MW, Lamontagne LL, Hepworth JT. Coping and depressive symptoms in adults living with heart failure. J Cardiovasc Nurs 2007;22:125-30.

35. Nicholas MK, Coulston CM, Asghari A, et al. Depressive symptoms in patients with chronic pain. Med. J. Aust 2009;190:S66-70.

36. Ayala-Feliciano M, Pons-Valerio JJ, Pons-Madera J, et al. The Relationship between Visuospatial Memory and Coping Strategies in Breast Cancer Survivors. Breast Cancer (Auckl) 2011; 5:117-30.

37. Xie L, Chen P, Pan $\mathrm{H}$, et al. Prevalence and correlates of suicidal ideation in SLE inpatients: Chinese experience. Rheumatol Int 2012;32:2707-14.

38. Haupt M, Millen S, Jänner M, et al. Improvement of coping abilities in patients with systemic lupus erythematosus: a prospective study. Ann Rheum Dis 2005;64:1618-23.

39. Fischer-Betz R, Wessel E, Richter J, et al. [Lupus in Germany: analysis within the German lupus self-help organization (LULA)]. Z Rheumatol 2005;64:111-22.

40. Ware J, Kosinski M, Keller SD. A 12-Item Short-Form Health Survey: construction of scales and preliminary tests of reliability and validity. Med Care 1996;34:220-33.

41. Karlson EW, Daltroy LH, Rivest C, et al. Validation of a Systemic Lupus Activity Questionnaire (SLAQ) for population studies. Lupus 2003;12:280-6.

42. Frey I, Berg A, Grathwohl D, et al. Freiburg Questionnaire of physical activity-development, evaluation and application. Soz Praventivmed 1999;44:55-64.

43. Flor H, Behle DJ, Birbaumer N. Assessment of pain-related cognitions in chronic pain patients. Behav Res Ther 1993;31: 63-73.

44. Tayer WG, Nicassio PM, Weisman MH, et al. Disease status predicts fatigue in systemic lupus erythematosus. J Rheumatol 2001;28:1999-2007.

45. Gladman D, Ginzler E, Goldsmith C, et al. The development and initial validation of the Systemic Lupus International Collaborating Clinics/American College of Rheumatology damage index for systemic lupus erythematosus. Arthritis Rheum 1996;39:363-9.

46. Gladman DD, Urowitz $\mathrm{MB}$, Goldsmith $\mathrm{CH}$, et al. The reliability of the Systemic Lupus International Collaborating Clinics/American College of Rheumatology Damage Index in patients with systemic lupus erythematosus. Arthritis Rheum 1997;40:809-13.

47. Gladman DD, Goldsmith $\mathrm{CH}$, Urowitz $\mathrm{MB}$, et al. The Systemic Lupus International Collaborating Clinics/American College of Rheumatology (SLICC/ACR) Damage Index for Systemic Lupus Erythematosus International Comparison. J. Rheumatol 2000;27:373-6.

48. Hurst NP, Ruta DA, Kind P. Comparison of the MOS short form-12 (SF12) health status questionnaire with the SF36 in patients with rheumatoid arthritis. Br J Rheumatol 1998;37:862-9.

49. Jenkinson $C$, Layte $R$, Jenkinson $D$, et al. A shorter form health survey: can the SF-12 replicate results from the SF-36 in longitudinal studies? J Public Health Med 1997;19:179-86.

50. Kiely KM, Butterworth P. Validation of four measures of menta health against depression and generalized anxiety in a community based sample. Psychiatry Res 2015;225:291-8.

51. Ware JE. SF-36 health survey: Manual and interpretation guide. Boston, MA: The Health Inst. New England Med. Center 1993.

52. Liang $\mathrm{MH}$, Socher SA, Larson MG, et al. Reliability and validity of six systems for the clinical assessment of disease activity in systemic lupus erythematosus. Arthritis Rheum 1989;32:1107-18.

53. Yazdany J, Yelin EH, Panopalis $\mathrm{P}$, et al. Validation of the systemic lupus erythematosus activity questionnaire in a large observational cohort. Arthritis Rheum 2008;59:136-43

54. Chehab G, Richter J, Sander O, et al. Validation and evaluation of the German version of the Systemic Lupus Activity Questionnaire (SLAQ). Clin Exp Rheumatol 2015;33:354-9.

55. Ruscheweyh R, Nees F, Marziniak M, et al. Pain catastrophizing and pain-related emotions: influence of age and type of pain. Clin J Pain 2011:27:578-86.

56. Buck K. The influence of flupirtine on the peripheral pain threshold at patients with fibromyalgia. Tübingen, Univ., Diss 2007.

57. Osthus AA, Aarstad AKH, Olofsson J, et al. Comorbidity is an independent predictor of health-related quality of life in a longitudinal cohort of head and neck cancer patients. Eur Arch Otorhinolaryngol 2013;270:1721-8.

58. Singh JA, Lewallen DG. Medical and psychological comorbidity predicts poor pain outcomes after total knee arthroplasty. Rheumatology (Oxford) 2013;52:916-3.

59. Yell JA, Mbuagbaw J, Burge SM. Cutaneous manifestations of systemic lupus erythematosus. Br J Dermatol 1996;135:355-62. 
60. Asano NMJ, Coriolano MdGWdS, Asano BJ, et al. Psychiatric comorbidities in patients with systemic lupus erythematosus: a systematic review of the last 10 years. Rev Bras Reumatol 2013:53:431-7.

61. Tian X, Zhang X. Gastrointestinal involvement in systemic lupus erythematosus: insight into pathogenesis, diagnosis and treatment. World J Gastroenterol 2010;16:2971-7.

62. Edwards RR, Bingham CO, Bathon J, et al. Catastrophizing and pain in arthritis, fibromyalgia, and other rheumatic diseases. Arthritis Rheum 2006;55:325-32.

63. Mancuso CA, Peterson MG, Charlson ME. Effects of depressive symptoms on health-related quality of life in asthma patients. $J$ Gen Intern Med 2000;15:301-10.

64. van Vollenhoven RF, Mosca M, Bertsias G, et al. Treat-to-target in systemic lupus erythematosus: recommendations from an international task force. Ann Rheum Dis 2014;73:958-67.
65. Buhrman M, Nilsson-Ihrfeldt E, Jannert M, et al. Guided internet-based cognitive behavioural treatment for chronic back pain reduces pain catastrophizing: a randomized controlled trial. J Rehabil Med 2011;43:500-5.

66. Riddle DL, Keefe FJ, Nay WT, et al. Pain coping skills training for patients with elevated pain catastrophizing who are scheduled for knee arthroplasty: a quasi-experimental study. Arch Phys Med Rehabil 2011;92:859-65.

67. Karlson $\mathrm{EW}$, Liang $\mathrm{MH}$, Eaton $\mathrm{H}$, et al. A randomized clinical trial of a psychoeducational intervention to improve outcomes in systemic lupus erythematosus. Arthritis Rheum 2004;50: 1832-41.

68. Williams EM, Penfield M, Kamen D, et al. An Intervention to Reduce Psychosocial and Biological Indicators of Stress in African American Lupus Patients: The Balancing Lupus Experiences with Stress Strategies Study. Open J Prev Med 2014;4:22-31. 